\title{
Adverse events among children in Canadian hospitals: the Canadian Paediatric Adverse Events Study
}

\author{
Anne G. Matlow MSc MD, G. Ross Baker PhD, Virginia Flintoft BN MSc, Douglas Cochrane MD, \\ Maitreya Coffey MD, Eyal Cohen MD, Catherine M.G. Cronin MD MBA, Rita Damignani MSc BScPT, \\ Robert Dubé MD, Roger Galbraith MD, Dawn Hartfield MD, Leigh Anne Newhook MD, \\ Cheri Nijssen-Jordan MD MBA
}

\section{- AbSTRACT \\ Background: Limited data are available on adverse events among children admitted to hospital. The Canadian Paediatric Adverse Events Study was done to describe the epi- demiology of adverse events among children in hospital in Canada.}

Methods: We performed a 2-stage medical record review at 8 academic pediatric centres and 14 community hospitals in Canada. We reviewed charts from patients admitted from April 2008 through March 2009, evenly distributed across 4 age groups ( 0 to $28 \mathrm{~d} ; 29$ to $365 \mathrm{~d} ;>1$ to $5 \mathrm{yr}$ and $>5$ to $18 \mathrm{yr}$ ). In stage 1 , nurses and health records personnel who had received training in the use of the Canadian Paediatric Trigger Tool reviewed medical records to detect triggers for possible adverse events. In stage 2, physicians reviewed the charts identified as having triggers and described the adverse events.

Results: A total of 3669 children were admitted to hospital during the study period. The weighted rate of adverse events was $9.2 \%$.

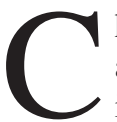
hildren are vulnerable to harm associated with medical care. Although there is a need to make health care safer, ${ }^{1}$ transforming the system requires knowledge of the full scope and burden of health careassociated injury in pediatric medicine. Chart and administrative database reviews showing rates of adverse events of $3 \%$ or lower among children admitted to hospital ${ }^{2-4}$ have been superseded by data from targeted studies using trigger tools to identify patient charts warranting review for adverse events. ${ }^{5-7}$ Unfortunately, the absence of a comprehensive pediatric trigger tool has limited the understanding of the full burden of health care-associated harm.
Adverse events were more frequent in academic pediatric centres than in community hospitals (adjusted odds ratio [OR] 2.98, 95\% confidence interval $[\mathrm{Cl}]$ 1.65-5.39). The incidence of preventable adverse events was not significantly different between types of hospital, but nonpreventable adverse events were more common in academic pediatric centres (adjusted OR 4.39, 95\% Cl 2.08-9.27). Surgical events predominated overall and occurred more frequently in academic pediatric centres than in community hospitals $(37.2 \%$ v. $21.5 \%$, relative risk [RR] 1.7, 95\% Cl 1.0-3.1), whereas events associated with diagnostic errors were significantly less frequent $(11.1 \%$ v. $23.1 \%$, RR $0.5,95 \% \mathrm{Cl} 0.2-0.9)$.

Interpretation: More children have adverse events in academic pediatric centres than in community hospitals; however, adverse events in the former are less likely to be preventable. There are many opportunities to reduce harm affecting children in hospital in Canada, particularly related to surgery, intensive care and diagnostic error.

The Canadian Paediatric Trigger Tool was validated to identify adverse events in children admitted to hospital. ${ }^{8}$ Using this tool, we conducted the Canadian Paediatric Adverse Events Study to determine and compare the incidence, type, severity and preventability of adverse events among children admitted to academic pediatric centres with those admitted to community hospitals in Canada.

\section{Methods}

\section{Design}

We designed a cross-sectional study using retrospective chart review based on the original Har-
Competing interests: Most of the authors (Baker, Cronin, Dubé, Flintoft, Galbraith, Hartfield, Matlow, Newhook) received support for travel and accommodation at studyrelated stakeholder meetings. Anne Matlow has received support for travel and meetings from the Canadian Patient Safety Institute. Douglas Cochrane is the chair of the Patient Safety and Quality Council for British Columbia and has received an honorarium for speaking at the

University of Calgary Patient Safety and Quality course. Maitreya Coffey received grant funding from the Canadian Patient Safety Institute. Eyal Cohen is a

paid member of the Committee to Evaluate Drugs for the Ontario Ministry of Health and Long-Term Care. Catherine Cronin received salary support from the Winnipeg Regional Health Authority and the University of

Manitoba during the study. Cheri Nijssen-Jordan is a consultant and senior medical lead with Alberta Health Services. No other competing interests were declared.

This article has been peer reviewed.

Correspondence to:

Anne G. Matlow, anne.matlow@wchospital.ca

CMAJ 2012. DOI:10.1503 /cmaj.112153 
vard Medical Practice Study protocol and its derivatives. ${ }^{9-17}$ The ethics boards of the University of British Columbia, University of Alberta, University of Calgary, University of Manitoba, University of Toronto, Dalhousie University and Memorial University approved the study. We obtained ethics approval from the local hospitals where required.

\section{Study sample}

We established 7 geographic nodes, each of which consisted of 1 academic pediatric centre and 2 community hospitals (Appendix 1, available at www.cmaj.ca/lookup/suppl/doi:10.1503 /cmaj.112153/-/DC1). One node included 2 smaller academic centres owing to the lower provincial populations in that area.

We defined academic pediatric centres as pediatric hospitals with a full-time core postgraduate training program in pediatrics and pediatric surgery in addition to a level 3 neonatal intensive care unit (ICU). Participating academic pediatric centres contributed to the cost of training reviewers and auditing charts locally. Two of the 10 academic pediatric centres declined the invitation to participate in the study and were not replaced.

Community hospitals were eligible for inclusion if they had 1000 or more pediatric admissions (including newborns) from April 2008 through March 2009 (fiscal year 2008/09), a neonatal ICU or special care nursery, and no fulltime core pediatric or pediatric surgical residency training. We limited the sample, where possible, to hospitals within $250 \mathrm{~km}$ of the node's academic pediatric centre. One of the community hospitals that was invited to participate could not obtain ethics approval, and the next community hospital for that node was substituted.

Participating hospitals consented to local chart audit. In total, 240 charts per academic site (120 per Atlantic site) and 140 per community hospital yielded 3640 hospital admissions for review, with the power to detect a real difference in the incidence of adverse events between types of hospital assuming an incidence of $15 \%(\alpha=0.05, \beta=$ $0.90)$. We ensured oversampling to allow for unavailability of $10 \%$ of charts.

Using a standardized algorithm, the decision support or health/medical records analysts selected a stratified random sample of admissions (patient charts) for each participating hospital. Admissions for patients less than 19 years of age with a stay in hospital lasting 24 hours or more were eligible for inclusion in our study. We excluded patients with a most responsible diagnosis related to obstetrics or psychiatry, those who died within 24 hours of admission and those (except newborns) who were trans- ferred from or to another acute care hospital during the index admission.

Patients were selected randomly from 4 predetermined age groups: 0-28 days (newborns), 29365 days, older than 1 year to 5 years of age, and older than 5 years to 18 years of age. The chart sample selected for newborns reflected the proportion of newborns in Canada admitted to neonatal ICUs for 24 hours or more $(12.8 \%$, as shown in the Discharge Abstract Database, 20072008). For patients who were not newborns, we sampled charts from medicine and surgery. We weighted adverse event results to reflect the national 2008 ratio for pediatric admissions to medicine and surgery $(2: 1)$ based on partition codes in the Discharge Abstract Database.

\section{Primary outcome}

Our primary outcome was an adverse event that occured within 3 months of the index admission and was detected during that stay in hospital or within 3 months of discharge from hospital. We defined an adverse event as an unintended injury or complication caused by health care management resulting in disability at discharge, death, prolonged stay in hospital or a subsequent admission to hospital. ${ }^{9-17}$ We defined "health care management" as including the decisions and actions of individual members of hospital staff in addition to the broader systems and processes of care. Physician reviewers assessed cause and preventability using a structured review of patient records. To qualify as an adverse event, the event was judged by the physician reviewer as more than $50 \%$ likely to have been caused by health care management. We considered adverse events to be preventable if judged to have been more than $50 \%$ preventable.

The incidence of adverse events was defined as the weighted percentage (by provincial distribution of pediatric patients by hospital type) of patients with an adverse event.

\section{Data collection}

We conducted a 2-stage review of medical records. In stage 1, a nurse or health record technologist (or a medical records technician in Quebec) at each site reviewed all charts for triggers using the Canadian Paediatric Trigger Tool (Appendix 2, available at www.cmaj.ca/lookup /suppl/doi:10.1503/cmaj.112153/-/DC1). Reviewers at this stage collected information on preadmission medical status (number and type of medications, dependency on a technological device [defined as a device such as a tracheotomy tube that, were it to fail or its use be stopped, would likely cause a sufficiently adverse health consequence $]^{18}$ and presence of a complex chronic 
condition [a medical condition lasting for 12 months involving several different organ systems, or a single organ system and requiring a high level of specialty care and admission to hospital, such as cystic fibrosis]). ${ }^{19}$ In stage 2, a physician reviewed charts for which triggers had been identified for adverse events. The reviewers during this stage classified each event according to cause, preventability, most responsible provider service and related procedures and events.

Before starting the study, all of the reviewers participated in a 2-day training session in which 19 anonymized pediatric hospital charts were reviewed using a customized training manual. We determined the proportion agreement on each of the cases addressed during training. During stage 1 , agreement was based on whether the reviewer selected one or more triggers or no triggers (trigger positive v. trigger negative); for stage 2, agreement was based on whether the physician designated each case as having had an adverse event.

The reviewers entered the data directly into a secure web-based database at the University of Toronto Institute of Health Policy, Management and Evaluation and stored for later analysis.

\section{Statistical analysis}

We calculated the number and percentage of charts from stage 1 with a positive result for any of the 35 triggers identified using the tool (Appendix 2). We analyzed the data from stage 2 to determine the incidence and preventability of adverse events, including their distribution by type of hospital (academic pediatric centre v. community hospital), age group, degree of harm and responsible service, and the factors to which they were related.

To determine the Canadian incidence of adverse events for our population sample, we calculated national point estimates and $95 \%$ con- fidence intervals (CIs) using a 2-stage stratified sampling technique, and weighted the results for the total number of charts per hospital, then for hospitals per type in each province. Data from the Canadian Institute for Health Information informed all weighting. We calculated relative risk (RR) and 95\% confidence intervals (CIs) to compare the incidence of adverse events between the two types of hospital.

We used logistic regression and adjusted for preadmission medical status to calculate the risk of an adverse event across age groups and types of hospital. We used similar logistic regression models to determine the preventability of adverse events.

\section{Results}

Significantly more patient charts from academic pediatric centres than from community hospitals were trigger-positive $(38.8 \%$ v. $21.6 \%$, RR 1.8 , 95\% CI 1.6-2.0) (Figure 1, Table 1). In total, 237 patients had adverse events during the study period. Of these, 4 patients died $(4 / 237=1.7 \%)$, all of whom had been admitted to academic pediatric centres (Table 2). Patients were significantly more likely to have an adverse event in an academic pediatric centre regardless of age $(0-5$ yr RR 3.8, 95\% CI 2.7-5.6; > 5 yr RR 2.0, 95\% CI 1.2-3.2) (Appendix 3, available at www.cmaj .ca/lookup/suppl/doi:10.1503/cmaj.112153/-/

DC1). The proportion agreement among the nurses for trigger-positive charts was $87 \%(95 \%$ CI 83\%-90\%); among physician reviewers, the proportion agreement for adverse events was $66 \%$ (95\% CI 57\%-76\%).

Of patients who had adverse events, $44.7 \%$ (106/237) had at least 1 adverse event that was preventable (Table 1); the proportion of preventable events was higher in community hospitals (RR 0.6, 95\% CI 0.4-0.8) and across all age

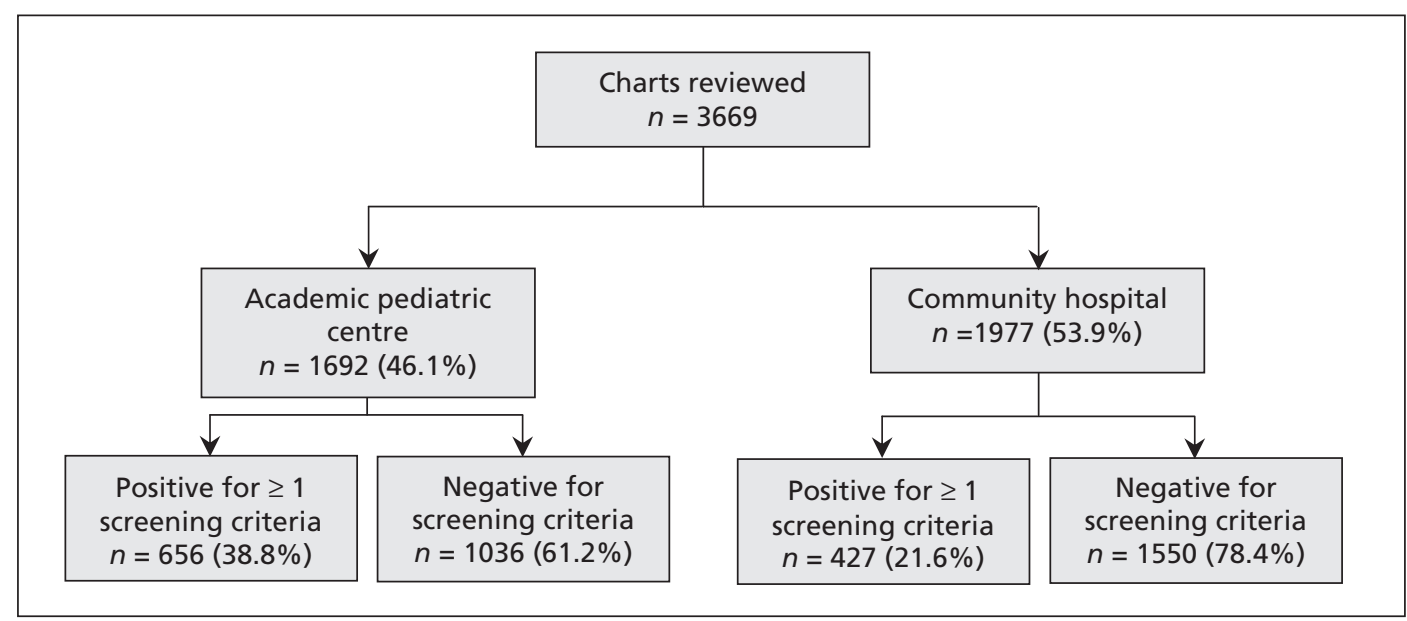

Figure 1: Review process for patient charts included in the study, by type of hospital. 
groups, with the exception of newborns (Appendix 3).

After weighting for the sampling frame, the overall rate of adverse events was $9.2 \%$ (95\% CI $5.1 \%-13.3 \%$ ) (Table 1). Children in academic pediatric centres had significantly more adverse events than those in community hospitals $(11.2 \%$ [95\% CI $6.4 \%-15 . \% 9]$ v. $3.3 \%$ [95\% CI $1.2 \%-$ $5.3 \%]$ ) (Table 1), but the difference in the weighted proportion of preventable adverse events between academic pediatric centres and community hospitals $(4.1 \%$ [95\% CI $1.2 \%-7.0 \%]$ v. $2.0 \%$ [ $95 \%$ CI $0.001 \%-4.0 \%]$ ) was nonsignificant (Table 1). Significantly fewer events in academic pediatric centres than in community hospitals resulted in temporary harm requiring a prolonged stay in hospital $(58.6 \%$ v. $75.4 \%$, RR $0.8,95 \%$ CI $0.7-1.0$ ), as well as recovery from event-related one-month impairment (42.4\% v. $60.9 \%$, RR 0.7 , 95\% CI 0.6-0.9) (Table 2).

Overall, the clinical services most responsible for the patients when adverse events occurred were surgery $(35.1 \%)$, medicine $(29.8 \%)$ and the ICU (13.3\%) (Table 3). With the exception of medicine, attributing adverse events to a responsible service differed significantly between the 2 types of hospital; surgery (RR 2.9, 95\% CI 1.65.7) and the ICU (RR 5.6, 95\% CI 1.4-34.4) predominated in academic centres, whereas emergency (RR 0.4, 95\% CI 0.2-0.8) and maternity/ obstetrics (RR 0.3, 95\% CI 0.1-0.8) predominated in community hospitals. Adverse events in newborns occurred less often in surgery compared with all other age groups (Appendix 3).

The factors related to adverse events differed between academic pediatric centres and community hospitals (Table 4).

Logistic regression showed that the odds ratio (OR) for having an adverse event was significantly higher in academic pediatric centres than in community hospitals (unadjusted OR 3.31, 95\% CI 2.54-4.53; adjusted OR 2.98, 95\% CI 1.65-5.39) (Table 5). Variables relating to medical status before admission were independently associated with having an adverse event (Table 5). The incidence of preventable adverse events was not significantly different between the 2 types of hospital. Nonpreventable adverse events were more common in academic pediatric centres than in community hospitals (adjusted OR 4.39, 95\% CI 2.08-9.27) (Table 5).

Newborns in neonatal ICUs had significantly higher rates of adverse events than those not in neonatal ICUs (Appendix 3). Among children more than 28 days old, the weighted proportion of preventable events was significantly higher among surgical than among medical patients (Appendix 3). Our analysis of adverse events by age group and type of hospital (Appendix 3) showed most adverse events related to "other clinical management" occurred in newborns. Children under 1 year of age accounted for $75.0 \%$ of adverse events related to medical procedures (RR 16.8, 95\% CI 8.8-31.5), whereas

Table 1: Rates of triggers, adverse events (weighted and unweighted), and preventable and non-preventable adverse events, overall and by type of hospital

\begin{tabular}{|c|c|c|c|c|}
\hline \multirow[b]{3}{*}{ Variable } & \multicolumn{3}{|c|}{ No. of patients $(\%)$ * } & \multirow[b]{3}{*}{$\mathrm{RR}(95 \% \mathrm{Cl})$} \\
\hline & \multirow[b]{2}{*}{$\begin{array}{c}\text { Overall } \\
n=3669\end{array}$} & \multicolumn{2}{|c|}{ Type of hospital† } & \\
\hline & & $\begin{array}{c}\text { Academic } \\
n=1692\end{array}$ & $\begin{array}{c}\text { Community } \\
n=1977\end{array}$ & \\
\hline Patients with $\geq 1$ trigger & $1083(29.5)$ & $656(38.8)$ & $427(21.6)$ & $1.8(1.6-2.0)$ \\
\hline \multirow[t]{2}{*}{ Patients with an adverse event } & $237 \quad(6.5)$ & $172(10.2)$ & $65 \quad(3.3)$ & $3.1(2.3-4.1)$ \\
\hline & $n=237$ & $n=172$ & $n=65$ & \\
\hline Patients with a preventable adverse event & $106(44.7)$ & $66(38.4)$ & $40(61.5)$ & $0.6(0.4-0.8)$ \\
\hline \multirow[t]{2}{*}{ Patients with a nonpreventable adverse event } & $131(55.3)$ & $106(61.6)$ & $25(38.5)$ & $1.6(1.2-2.3)$ \\
\hline & $n=3669$ & $n=1692$ & $n=1977$ & \\
\hline Patients with $>1$ adverse event & $30(0.8)$ & $26(1.5)$ & $4 \quad(0.2)$ & $7.6(2.5-25.6)$ \\
\hline Weighted rate of adverse events, $\%(95 \% \mathrm{Cl}) \ddagger$ & $9.2(5.1-13.3)$ & $11.2(6.4-15.9)$ & $3.3(1.2-5.3)$ & NA§ \\
\hline Weighted rate of preventable adverse events, $\%(95 \% \mathrm{Cl})$ & $3.6(1.5-5.7)$ & $4.1(1.2-7.0)$ & $2.0(0.001-4.0)$ & NAף \\
\hline \multicolumn{5}{|c|}{$\begin{array}{l}\text { Note: } \mathrm{Cl}=\text { confidence interval, } \mathrm{NA}=\text { not applicable, } \mathrm{RR}=\text { relative risk. } \\
\text { *Unless otherwise indicated. } \\
\text { †The academic pediatric centre had a minimum of } 1000 \text { pediatric admissions in fiscal year } 2008 \text { and a full-time residency program in pediatric medicine and } \\
\text { surgery; the community hospital also had a minimum of } 1000 \text { pediatric admissions in fiscal year } 2008, \text { but did not offer a full-time residency program in both } \\
\text { pediatric medicine and surgery. } \\
\text { ¥Point estimates and Cls were weighted to account for the total number of charts per hospital and the total number of hospitals per type per province. } \\
\text { \$Relative risk is not available for weighted rates for comparison between types of hospital; } p<0.0001 \text {. } \\
\text { १Relative risk is not available for weighted rates for comparison between types of hospital; } p=0.1 \text {. }\end{array}$} \\
\hline
\end{tabular}


those older than 1 year accounted for $75.0 \%$ of the events related to drugs (RR 19.2, 95\% CI 9.7-37.7) (Appendix 3). In academic pediatric centres, children aged 29-365 days accounted for most of the adverse events related to surgeries $(48.0 \%)$ (Appendix 3). In community hospitals, children older than 5 years had the highest rates of adverse events related to surgery (64.3\%), diagnostic errors (46.7\%) and drugs (42.9\%) (Appendix 3).

The mean length of stay for patients with adverse events was significantly longer in academic pediatric centres (14.2 [95\% CI 10.7-17.7] d) than in community hospitals (5.6 [95\% CI 3.67.6] d) (data not shown). The corresponding mean lengths of stay among patients who did not have adverse events was 4.6 (95\% CI 4.3-5.0) d in academic pediatric centres and 3.4 (95\% CI 2.5-4.3) $\mathrm{d}$ in community hospitals (data not shown).

\section{Interpretation}

After weighting for our sampling frame, we found that significantly more children admitted to acade- mic pediatric centres than to community hospitals in Canada had adverse events. The predominance of adverse events in academic pediatric centres remained apparent after we adjusted for preadmission medical status (high-alert medications, dependency on a technological device and having a complex chronic condition). However, these variables, characteristic of children with complex medical conditions,$^{20}$ were each independently associated with adverse events. Overall, 9.2\% of children admitted to hospital had an adverse event. Adverse events related to surgery were the most frequent and predominantly occurred in academic pediatric centres. Diagnostic adverse events and those due to "other clinical management" were significantly more common in community hospitals. In community hospitals, adverse events in the emergency department were significantly more common among children aged $1-5$ years than among other age groups; medically related adverse events were significantly more common in children during the first year of life. Drug-related adverse events predominated in academic pediatric centres, with children aged more than 1 year to 5 years being the

Table 2: Degree of impairment and harm resulting from each adverse event, by type of hospital

\begin{tabular}{|c|c|c|c|c|c|}
\hline \multirow[b]{3}{*}{ Variable } & \multicolumn{4}{|c|}{ Adverse events, no. (\%) } & \multirow[b]{3}{*}{$\operatorname{RR}(95 \% \mathrm{Cl})$} \\
\hline & \multirow{2}{*}{\multicolumn{2}{|c|}{$\begin{array}{l}\text { Overall } \\
n=279\end{array}$}} & \multicolumn{2}{|c|}{ Type of hospital* } & \\
\hline & & & $\begin{array}{l}\text { Academic } \\
n=210\end{array}$ & $\begin{array}{c}\text { Community } \\
n=69\end{array}$ & \\
\hline \multicolumn{6}{|l|}{$\begin{array}{l}\text { Degree of impairment due to adverse } \\
\text { event }\end{array}$} \\
\hline No physical impairment & & (23.3) & $50(23.8)$ & $15(21.7)$ & $7.6(2.5-25.6)$ \\
\hline Recovery in $1 \mathrm{mo}$ & 131 & $(47.0)$ & $89(42.4)$ & $42(60.9)$ & $0.7(0.6-0.9)$ \\
\hline Recovery in $1-6$ mo & 39 & (14.0) & $33(15.7)$ & $6(8.7)$ & $1.8(0.8-4.7)$ \\
\hline Recovery in 6 mo to $1 \mathrm{y}$ & 2 & $(0.7)$ & $2(1.0)$ & $0 \quad(0.0)$ & $1.7(0.1-34.1)$ \\
\hline Permanent impairment, disability $1-50 \%$ & 12 & (4.3) & $11 \quad(5.2)$ & 1 (1.4) & $3.6(0.5-74.9)$ \\
\hline Permanent impairment, disability $>50 \%$ & 1 & $(0.4)$ & $1(0.5)$ & $0 \quad(0.0)$ & $1.0(0.0-24.2)$ \\
\hline Deatht & 7 & (2.5) & $7 \quad(3.3)$ & $0 \quad(0.0)$ & $5.0(0.3-86.0)$ \\
\hline Unable to determine & 22 & $(7.9)$ & $17(8.1)$ & $5(7.2)$ & $1.1(0.4-3.4)$ \\
\hline \multicolumn{6}{|l|}{ Degree of harm due to adverse event } \\
\hline $\begin{array}{l}\text { Temporary harm to the patient requiring } \\
\text { intervention }\end{array}$ & 46 & $(16.5)$ & $36(17.1)$ & $10(14.5)$ & $1.2(0.6-2.5)$ \\
\hline $\begin{array}{l}\text { Temporary harm to the patient requiring } \\
\text { initial or prolonged stay in hospital }\end{array}$ & 175 & (62.7) & $123(58.6)$ & $52(75.4)$ & $0.8(0.7-1.0)$ \\
\hline Permanent harm & 17 & (6.1) & $15(7.1)$ & $2(2.9)$ & $2.5(0.6-15.5)$ \\
\hline Intervention required to sustain life & 25 & $(9.0)$ & $21(10.0)$ & $4(5.8)$ & $1.7(0.6-5.9)$ \\
\hline Death $†$ & 7 & (2.5) & $7 \quad(3.3)$ & $0 \quad(0.0)$ & $5.0(0.3-86.0)$ \\
\hline No evidence of harm & 4 & (1.4) & $3(1.4)$ & $1(1.4)$ & $1.0(0.1-24.6)$ \\
\hline Missing data & 5 & $(1.8)$ & $5 \quad(2.4)$ & $0 \quad(0.0)$ & $3.6(0.2-65.2)$ \\
\hline \multicolumn{6}{|c|}{$\begin{array}{l}\text { Note: } \mathrm{Cl}=\text { confidence interval, } \mathrm{RR}=\text { relative risk. } \\
\text { *The academic pediatric centre had a minimum of } 1000 \text { pediatric admissions in fiscal year } 2008 \text { and a full-time residency } \\
\text { program in pediatric medicine and surgery; the community hospital also had a minimum of } 1000 \text { pediatric admissions in fiscal } \\
\text { year } 2008 \text {, but did not offer a full-time residency program in both pediatric medicine and surgery. } \\
\text { TThese } 7 \text { adverse events occurred in } 4 \text { patients. }\end{array}$} \\
\hline
\end{tabular}


most vulnerable. Compared with other age groups, children 5-18 years of age in community hospitals had the most adverse events related to surgery, diagnostics and drugs.

The higher rate of adverse events among children in academic pediatric centres has been reported previously $y^{2,3,21,22}$ and may be due to complexity of care, the higher number of caregivers, trainees and handovers, and different standards of documentation. The higher incidence of adverse events in newborns parallels previous reports of iatrogenic harm in neonatal ICUs. ${ }^{6,23}$ Children with complex medical conditions have emerged as a group with increased vulnerability to adverse events. We found a predominance of adverse events related to surgery. ${ }^{2,4}$ This high incidence in academic pediatric centres could be explained by the Canadian practice of performing most surgery in children under 5 years of age in such facilities.

Table 3: Most responsible service for delivery of care at the time of each of the 279 adverse events, overall and by type of hospital

\begin{tabular}{|c|c|c|c|c|}
\hline \multirow[b]{3}{*}{ Most responsible service } & \multicolumn{3}{|c|}{ Adverse events, no. (\%) } & \multirow[b]{3}{*}{$\operatorname{RR}(95 \% \mathrm{Cl})$} \\
\hline & \multirow[b]{2}{*}{$\begin{array}{l}\text { Overall* } \\
n=279\end{array}$} & \multicolumn{2}{|c|}{ Type of hospital } & \\
\hline & & $\begin{array}{c}\text { Academic } \\
n=210\end{array}$ & $\begin{array}{c}\text { Community } \\
n=69\end{array}$ & \\
\hline Surgery & $98(35.1)$ & $88(41.9)$ & $10(14.5)$ & $2.9(1.6-5.7)$ \\
\hline Medicine & $83(29.8)$ & $60(28.6)$ & $23(33.3)$ & $0.9(0.6-1.3)$ \\
\hline Emergency & $23 \quad(8.2)$ & $12(5.7)$ & $11(15.9)$ & $0.4(0.2-0.8)$ \\
\hline ICU & $37(13.3)$ & $35(16.7)$ & $2(2.9)$ & $5.6(1.4-34.4)$ \\
\hline Maternal/obstetrics & $15 \quad(5.4)$ & 7 (3.3) & $8(11.6)$ & $0.3(0.1-0.8)$ \\
\hline Other & $23 \quad(8.2)$ & $8(3.8)$ & $15(21.7)$ & $0.2(0.1-0.4)$ \\
\hline \multicolumn{5}{|c|}{$\begin{array}{l}\text { Note: } \mathrm{Cl}=\text { confidence interval, ICU = intensive care unit, } \\
\mathrm{RR}=\text { relative risk. } \\
\text { *Physician reviewers identified the clinical service responsible for patient care at the time that the adverse event occurred. For } \\
\text { patients who experienced more than } 1 \text { adverse event, the most responsible clinical service may have differed for each or some } \\
\text { of the adverse events. Therefore, results in this table are reported at the level of adverse events }(n=279) \text { for the } 237 \text { patients } \\
\text { who had } 1 \text { or more adverse events. }\end{array}$} \\
\hline
\end{tabular}

Table 4: Distribution of adverse events among 237 patients, grouped by factor to which the event was related, overall and by type of hospital

\begin{tabular}{|c|c|c|c|c|}
\hline \multirow[b]{3}{*}{ Factor related to event } & \multicolumn{3}{|c|}{ Patients, no. $(\%)^{*}$} & \multirow[b]{3}{*}{$\mathrm{RR}(95 \% \mathrm{Cl})$} \\
\hline & \multirow[b]{2}{*}{$\begin{array}{l}\text { Overall } \\
n=237\end{array}$} & \multicolumn{2}{|c|}{ Hospital type } & \\
\hline & & $\begin{array}{c}\text { Academic } \\
n=172\end{array}$ & $\begin{array}{c}\text { Community } \\
n=65\end{array}$ & \\
\hline Surgical & $78(32.9)$ & $64(37.2)$ & $14(21.5)$ & $1.7(1.0-3.1)$ \\
\hline Other clinical management $\dagger$ & $47(19.8)$ & $29(16.9)$ & $18(27.7)$ & $0.6(0.4-1.1)$ \\
\hline Medical procedure & $36(15.2)$ & $30(17.4)$ & $6 \quad(9.2)$ & $1.9(0.8-4.9)$ \\
\hline Diagnostic error & $34(14.4)$ & $19(11.1)$ & $15(23.1)$ & $0.5(0.2-0.9)$ \\
\hline Drug & $32(13.5)$ & $25(14.5)$ & $7(10.7)$ & $1.4(0.6-3.3)$ \\
\hline Anaesthesia & $6 \quad(2.5)$ & $5 \quad(2.9)$ & $1 \quad(1.5)$ & $1.9(0.2-42.7)$ \\
\hline Adverse event not covered elsewhere & $3(1.3)$ & $2(1.2)$ & $1(1.5)$ & $0.8(0.1-21.0)$ \\
\hline Fluid & $2(0.8)$ & $1 \quad(0.6)$ & $1(1.5)$ & $0.4(0.0-13.8)$ \\
\hline Fracture & $2(0.8)$ & $2(1.2)$ & $0 \quad(0.0)$ & $1.9(0.1-39.2)$ \\
\hline None & $3 \quad(1.3)$ & $3 \quad(1.7)$ & $0 \quad(0.0)$ & $2.7(0.1-51.0)$ \\
\hline Unable to determine & $13 \quad(5.5)$ & $8 \quad(4.7)$ & $5 \quad(7.7)$ & $0.6(0.2-2.1)$ \\
\hline \multicolumn{5}{|c|}{$\begin{array}{l}\text { Note: } \mathrm{Cl}=\text { confidence interval, } \mathrm{RR}=\text { relative risk. } \\
\text { *Reviewers selected as many categories as applied when classifying procedures and events. Percentages in this table are basec } \\
\text { on total number of patients in the section (e.g., academic, community); as a result, the sum of the percentages is not } 100 \% \text {. } \\
\text { tIncludes failure of labour to progress or fetal distress resulting in emergency cesarean delivery, inappropriate discharge and } \\
\text { inappropriate treatment by primary care giver. }\end{array}$} \\
\hline
\end{tabular}


The overall incidence of drug-related events in our study was lower than the $11.1 \%$ reported using a trigger tool specific to drug-related adverse events ${ }^{5}$ and is closer to that reported in other studies of pediatric adverse drug events. ${ }^{24,25}$ This difference could be explained by the high threshold of harm we used for ascribing an adverse event. As drug-related events accounted for only $13.5 \%$ of all adverse events in our study, a wide-lens approach to improving pediatric patient safety is needed, of which safe medication delivery is but one component.

Adverse events attributed to visits to the emergency department were more common in community hospitals than in academic pediatric centres, as were diagnostic adverse events. Diagnostic errors are recognized hazards in pediatric emergency care, partly owing to emergency department physicians in community hospitals being more familiar with adult medicine than pediatric

Table 5 (part 1 of 2): Logistic regression* modelled on all adverse events, preventable adverse events and nonpreventable adverse events

\begin{tabular}{|c|c|c|c|}
\hline Variable & Adverse events, $\%(n / N)$ & $\begin{array}{l}\text { Unadjusted } \\
\text { OR }(95 \% \mathrm{Cl})\end{array}$ & $\begin{array}{c}\text { Adjusted } \\
\text { OR }(95 \% \mathrm{Cl})\end{array}$ \\
\hline \multicolumn{4}{|c|}{ Modelled on all adverse events } \\
\hline \multicolumn{4}{|c|}{ Hospital type } \\
\hline Academic pediatric centre & $10.2(172 / 1692)$ & $3.31(2.54-4.53)$ & $2.98(1.65-5.39)$ \\
\hline Community hospital & $3.3(65 / 1977)$ & 1.00 & 1.00 \\
\hline \multicolumn{4}{|l|}{ Age group } \\
\hline $0-28 d$ & $5.7 \quad(53 / 927)$ & $0.78(0.54-1.13)$ & $0.91(0.51-1.60)$ \\
\hline $29-365 d$ & $6.9(62 / 902)$ & $0.95(0.66-1.35)$ & $0.93(0.64-1.35)$ \\
\hline $366 \mathrm{~d}-5 \mathrm{yr}$ & $6.0(54 / 900)$ & $0.82(0.57-1.18)$ & $0.81(0.56-1.17)$ \\
\hline$>5-18 \mathrm{yr}$ & $7.2(68 / 940)$ & 1.00 & 1.00 \\
\hline \multicolumn{4}{|c|}{ Taking prescription medication before admission $†$} \\
\hline One or more & $12.0 \quad(28 / 234)$ & $2.10(1.38-3.19)$ & $1.01(0.62-1.65)$ \\
\hline None & $6.1(209 / 3435)$ & 1.00 & 1.00 \\
\hline \multicolumn{4}{|c|}{ Using high-alert medications before admission‡ } \\
\hline One or more & $12.9(38 / 295)$ & $2.36(1.63-3.41)$ & $1.47(1.02-2.13)$ \\
\hline None & $5.9(199 / 3374)$ & 1.00 & 1.00 \\
\hline \multicolumn{4}{|c|}{ Device dependency before admission§ } \\
\hline One or more & $15.3 \quad(20 / 131)$ & $2.76(1.68-4.53)$ & $1.54(1.01-2.35)$ \\
\hline None & $6.5(217 / 3321)$ & 1.00 & 1.00 \\
\hline \multicolumn{4}{|c|}{ Complex chronic condition on admissionף } \\
\hline One or more & $11.0 \quad(55 / 500)$ & $2.03(1.48-2.79)$ & $1.62(1.13-2.33)$ \\
\hline None & $5.7(182 / 3169)$ & 1.00 & 1.00 \\
\hline \multicolumn{4}{|c|}{ Modelled on preventable adverse events } \\
\hline \multicolumn{4}{|l|}{ Hospital type } \\
\hline Academic pediatric centre & $(66 / 1692)$ & $1.97(1.32-2.93)$ & $1.92(0.80-4.61)$ \\
\hline Community hospital & $2.0 \quad(40 / 1977)$ & 1.00 & 1.00 \\
\hline \multicolumn{4}{|l|}{ Age group } \\
\hline $0-28 d$ & $2.4 \quad(22 / 927)$ & $0.58(0.34-0.98)$ & $0.60(0.23-1.51)$ \\
\hline $29-365 d$ & $2.4 \quad(22 / 902)$ & $0.59(0.35-1.01)$ & $0.59(0.29-1.20)$ \\
\hline $366 \mathrm{~d}-5 \mathrm{yr}$ & $(24 / 900)$ & $0.65(0.39-1.09)$ & $0.65(0.34-1.23)$ \\
\hline$>5-18 \mathrm{yr}$ & $(38 / 940)$ & 1.00 & 1.00 \\
\hline \multicolumn{4}{|c|}{ Taking prescription medication before admission $†$} \\
\hline One or more & $(11 / 234)$ & $1.73(0.92-3.28)$ & $1.35(0.60-3.04)$ \\
\hline None & $2.8 \quad(95 / 3435)$ & 1.00 & 1.00 \\
\hline \multicolumn{4}{|c|}{ Using high-alert medications before admission $\ddagger$} \\
\hline One or more & $3.4(10 / 295)$ & $1.20(0.62-2.32)$ & $0.71(0.30-1.65)$ \\
\hline None & $2.8(96 / 3374)$ & 1.00 & 1.00 \\
\hline
\end{tabular}


Table 5 (part 2 of 2): Logistic regression* modelled on all adverse events, preventable adverse events and non-preventable adverse events

\begin{tabular}{|c|c|c|c|}
\hline Variable & Adverse events, $\%(n / N)$ & $\begin{array}{l}\text { Unadjusted } \\
\text { OR }(95 \% \mathrm{Cl})\end{array}$ & $\begin{array}{c}\text { Adjusted } \\
\text { OR }(95 \% \mathrm{Cl})\end{array}$ \\
\hline \multicolumn{4}{|c|}{ Device dependency before admission§ } \\
\hline One or more & $(7 / 131)$ & $1.96(0.89-4.31)$ & $1.53(0.46-5.08)$ \\
\hline None & $2.8 \quad(99 / 3538)$ & 1.00 & 1.00 \\
\hline \multicolumn{4}{|c|}{ Complex chronic condition on admission? } \\
\hline One or more & $3.6(18 / 500)$ & $1.31(0.78-2.19)$ & $1.12(0.60-2.09)$ \\
\hline None & $2.8 \quad(88 / 3169)$ & 1.00 & 1.00 \\
\hline \multicolumn{4}{|c|}{ Modelled on non-preventable adverse events } \\
\hline \multicolumn{4}{|l|}{ Type of hospital } \\
\hline Academic pediatric centre & $6.3(106 / 1692)$ & $5.22(3.36-8.11)$ & $4.39(2.08-9.27)$ \\
\hline Community hospital & $1.3 \quad(25 / 1977)$ & 1.00 & 1.00 \\
\hline \multicolumn{4}{|l|}{ Age group } \\
\hline $0-28 d$ & $3.3(31 / 927)$ & $1.05(0.63-1.75)$ & $1.37(0.78-2.40)$ \\
\hline $29-365 d$ & $4.4 \quad(40 / 902)$ & $1.41(0.87-2.28)$ & $1.38(0.89-2.14)$ \\
\hline $366 \mathrm{~d}-5 \mathrm{yr}$ & $3.3(30 / 900)$ & $1.05(0.62-1.75)$ & $1.04(0.63-1.73)$ \\
\hline$>5-18 \mathrm{yr}$ & $3.2(30 / 940)$ & 1.00 & 1.00 \\
\hline \multicolumn{4}{|c|}{ Taking prescription medication before admission $\dagger$} \\
\hline One or more & $7.3(17 / 234)$ & $2.28(1.35-3.87)$ & $0.85(0.47-1.54)$ \\
\hline None & $3.3(114 / 3435)$ & 1.00 & 1.00 \\
\hline \multicolumn{4}{|c|}{ Use of high-alert medications before admission $\ddagger$} \\
\hline One or more & $9.5 \quad(28 / 295)$ & $3.34(2.15-5.15)$ & $2.17(1.18-3.97)$ \\
\hline None & $3.1(103 / 3374)$ & 1.00 & 1.00 \\
\hline \multicolumn{4}{|c|}{ Device dependency before admission§ } \\
\hline One or more & $9.9 \quad(13 / 131)$ & $3.19(1.75-5.83)$ & $1.51(0.71-3.25)$ \\
\hline None & $3.3(118 / 3538)$ & 1.00 & 1.00 \\
\hline \multicolumn{4}{|c|}{ Complex chronic condition on admission } \\
\hline One or more & $7.4 \quad(37 / 500)$ & $2.61(1.76-3.87)$ & $1.98(1.41-2.77)$ \\
\hline None & $3.0 \quad(94 / 3169)$ & 1.00 & 1.00 \\
\hline \multicolumn{4}{|c|}{$\begin{array}{l}\text { Note: } \mathrm{Cl}=\text { confidence interval, } \mathrm{OR}=\text { odds ratio. } \\
\text { *The variables in the logistic regression model include type of hospital, age group, number and type of medications, dependency on a technological device (i.e., a } \\
\text { device that, were it to fail or its use discontinued, would likely cause an adverse health consequence [e.g., a tracheostomy tube]), and presence of a complex chro } \\
\text { condition (i.e., a medical condition that lasts for } 12 \text { mo and involves several different organ systems or a single organ system requiring a high level of specialty car } \\
\text { and admission to hospital [e.g. cystic fibrosis]]). These criteria were applied to newborns if the medication, device or complex condition was prescribed, instituted } \\
\text { diagnosed within } 24 \mathrm{~h} \text { of birth. } \\
\text { tMedication of any kind prescribed before the index admission. } \\
\text { fAny of the following high-alert medications prescribed before admission: anticoagulant agents, antiepileptic agents, medication for gastroesophageal reflux, } \\
\text { insulin, narcotics and/or vasoactive-cardiac medications. } \\
\text { §Use of one or more of the following devices before admission: indwelling medication pump/nutritional support (enteral or parenteral), renal support (urinary } \\
\text { catheter or dialysis), respiratory support (apnea monitor, home suction, pulse oximetry, tracheostomy, home oximetry), stoma care. } \\
\text { IDiagnosed before admission and representing children with complex chronic conditions in June 2008. }\end{array}$} \\
\hline
\end{tabular}

medicine and the lack of standardized emergency pediatric protocols. ${ }^{1}$

\section{Limitations}

Trigger tools use retrospective chart review, which is dependent on the quality of documentation and the subjective assessment of preventability. ${ }^{8}$ In addition, the threshold of harm we used to define an adverse event was similar to that used in national studies ${ }^{26}$ but higher than that used in previous pediatric studies. ${ }^{2,3,5,6}$ For this reason, our results reflect the more serious events but under- estimate the total harm in children admitted to hospital. By excluding transferred patients (with the exception of newborns), possibly those with more complex conditions and requiring tertiary care in an academic pediatric centre, we may have further underestimated total harm.

The variables we used to describe preadmission medical status provide only a limited view on the vulnerability of children with complex medical conditions.

Our findings may not be generalizable to all children admitted to hosptial in Canada because 
budgetary constraints precluded studying all provinces and territories. In addition, our sampling strategy precludes understanding the proportional distribution of adverse events by age across Canada, although it does permit direct comparison between age groups.

Finally, the designation of adverse events as preventable or nonpreventable was based on the professional judgment of the physician reviewers and could thus be subject to personal bias.

\section{Conclusion}

Many children have adverse events in Canadian hospitals. Children admitted to academic pediatric centres remain most vulnerable, particularly perioperatively and while in intensive care. In community hospitals, preventable hazards are of concern in the emergency department and maternity/obstetrics ward, as well as in clinical diagnostics.

Our findings are likely not unique to Canada. Risk factors for unsafe care in pediatrics are universal, including children's physical characteristics and developmental variability. ${ }^{27}$ We hope our results catalyze widespread efforts to improve the safety of pediatric health care in Canada.

\section{References}

1. American Academy of Pediatrics Steering Committee on Quality Improvement and Management and Committee on Hospital Care. Policy statement - principles of pediatric patient safety: reducing harm due to medical care. Pediatrics 2011;127:1199-210.

2. Miller MR, Elixhauser A, Zhan C. Patient safety events during pediatric hospitalizations. Pediatrics 2003;111:1358-66.

3. Slonim AD, LaFleur BJ, Ahmed W, et al. Hospital-reported medical errors in children. Pediatrics 2003;111:617-21.

4. Woods D, Thomas E, Holl J, et al. Adverse events and preventable adverse events in children. Pediatrics 2005;115:155-60.

5. Takata GS, Mason W, Taketomo C, et al. Development, testing, and findings of a pediatric-focused trigger tool to identify medication-related harm in US children's hospitals. Pediatrics 2008;121:e927-35.

6. Sharek PJ, Horbar JD, Mason W, et al. Adverse events in the neonatal intensive care unit: development, testing, and findings of an NICU-focused trigger tool to identify harm in North American NICUs. Pediatrics 2006;118:1332-40.

7. Larsen GY, Donaldson AE, Parker HB, et al. Preventable harm occurring to critically ill children. Pediatr Crit Care Med 2007; 8:331-6.

8. Matlow AG, Cronin CMG, Flintoft V, et al. Description of the development and validation of the Canadian Paediatric Trigger Tool. BMJ Qual Saf 2011;20:416-23.

9. Baker GR, Norton PG, Flintoft V, et al. The Canadian Adverse Events Study: the incidence of adverse events among hospital patients in Canada. CMAJ 2004;170:1678-86.

10. Brennan TA, Leape LL, Laird NM, et al. Incidence of adverse events and negligence in hospitalized patients. Results of the Harvard Medical Practice Study I. N Engl J Med 1991;324:370-6.

11. Leape LL, Brennan TA, Laird N, et al. The nature of adverse events in hospitalized patients. Results of the Harvard Medical Practice Study II. N Engl J Med 1991;324:377-84.

12. Wilson RM, Runciman WB, Gibberd RW, et al. The Quality in Australian Health Care Study. Med J Aust 1995;163:458-71.

13. Thomas EJ, Studdert DM, Burstin HR, et al. Incidence and types of adverse events and negligent care in Utah and Colorado. Med Care 2000;38:261-71.

14. Davis P, Lay-Yee R, Briant R, et al. Adverse events in New Zealand public hospitals: principal findings from a national survey. Wellington (New Zealand): Ministry of Health; 2001.

15. Vincent $\mathrm{C}$, Neale G, Woloshynowych M. Adverse events in British hospitals: preliminary retrospective record review. $B M J$ 2001;322:517-9.

16. Davis P, Lay-Yee R, Briant R, et al. Adverse events in New Zealand public hospitals I: occurrence and impact. N Z Med J 2002; 115:U271.

17. Davis P, Lay-Yee R, Briant R, et al. Adverse events in New Zealand public hospitals II: preventability and clinical context. $N Z$ Med J 2003;116:U624.

18. US Congress, Office of Technology Assessment. Technologydependent children: hospital $v$. home care - a technical memorandum, OTA-TM-H-38. Washington (DC): US Government Printing Office; 1987.

19. Feudtner C, Hays RM, Haynes G, et al. Deaths attributed to pediatric complex chronic conditions: national trends and implications for supportive care services. Pediatrics 2001;107:E99.

20. Cohen E, Kuo DZ, Agrawal A, et al. Children with medical complexity: an emerging population for clinical and research initiatives. Pediatrics 2011;127:529-38.

21. Miller MR, Zhan C. Pediatric patient safety in hospitals: a national picture in 2000. Pediatrics 2004;113:1741-6.

22. Kanter DE, Turenne W, Slonim AD. Hospital-reported medical errors in premature neonates. Pediatr Crit Care Med 2004;5: 119-23.

23. Kugelman A, Inbar-Sanado E, Shinwell ES, et al. Iatrogenesis in neonatal intensive care units: observational and interventional, prospective, multicenter study. Pediatrics 2008;122:550-5.

24. Kunac DL, Reith DM, Kennedy J, et al. Inter- and intra-rater reliability for classification of medication related events in pediatric inpatients. Qual Saf Health Care 2006;15:196-201.

25. Kaushal R, Bates DW, Landrigan C. Medication errors and adverse drug events in pediatric inpatients. JAMA 2001;285: 2114-20.

26. de Vries EN, Ramrattan MA, Smorenburg SM, et al. The incidence and nature of in-hospital adverse events: a systematic review. Qual Saf Health Care 2008;17:216-23.

27. Woods DM, Holl JL, Shonkoff JP, et al. Child-specific risk factors and patient safety. J Patient Saf 2005;1:17-22.

Affiliations: From the Department of Pediatrics (Matlow, Coffey, Cohen), Hospital for Sick Children; the Department of Pediatrics (Matlow, Coffey, Cohen), University of Toronto; University of Toronto Centre for Patient Safety (Matlow, Baker, Flintoft, Coffey, Cohen); Institute of Health Policy, Management and Evaluation (Baker, Flintoft), University of Toronto, Toronto, Ont.; the Department of Surgery (Cochrane), University of British Columbia; BC Patient Safety and Quality Council (Cochrane), Vancouver, BC; Child Health Program (Cronin), Winnipeg Regional Health Authority, Winnipeg, Man.; the Department of Quality and Risk Management (Damignani), Hospital for Sick Children, Toronto, Ont.; the Department of Paediatrics (Dubé), Centre Hospitalier Universitaire Ste-Justine, University of Montreal, Montréal, Que.; the Department of Pediatrics (Galbraith, Nijssen-Jordan), Faculty of Medicine, University of Calgary, Calgary, Alta; the Department of Pediatrics (Hartfield), University of Alberta, Edmonton, Alta.; the Discipline of Pediatrics (Newhook), Memorial University; and Janeway Child Healthcare Centre (Newhook), Eastern Health, St. John's, NL

Contributors: All of the authors contributed to the design and execution of the study. Anne Matlow, Ross Baker and Virginia Flintoft conceived and designed the study and provided ongoing monitoring. Anne Matlow and Virginia Flintoft interpreted the data and, together with Ross Baker, drafted the article. Douglas Cochrane, Maitreya Coffey, Eyal Cohen, Catherine Cronin and Robert Dubé analyzed and contributed to the interpretation of the data. Virginia Flintoft contributed to the design of the study instrument, the project manual and software development and revised the manuscript. Eyal Cohen guided the design of the database for collection of patient complexity data. Douglas Cochrane, Maitreya Coffey, Catherine Cronin, Rita Damignani, Robert Dubé, Roger Galbraith, Dawn Hartfield, Leigh Anne Newhook, and Cheri NijssenJordan acquired the data. All of the authors critically reviewed the manuscript for important intellectual content and approved the final version submitted for publication.

Funding: Funding for this study was provided by the Hospital for Sick Children Foundation, the Canadian Patient Safety Institute and the Molson Foundation. The study's sponsors had no role in the design of the study, the collection, analysis 
or interpretation of data, the writing of the report or the decision to submit the article for publication. Participating academic pediatric centres contributed a participation fee to the study and may be considered "minor sponsors." Their roles were limited to those of the medical and quality improvement leads from their organizations, some of whom are coauthors.

Acknowledgements: The authors thank Cheryl Crummel, Darlene Boliver, Marie-Suzanne Lavallée, Dr. Ann Bayliss, Jennifer Conlin, Josephine McKeever, Judy Komori, Sharon Penney, Stacy Burgess, Julie MacLean, Rena Pandya, Christiane Beauchamp, Lucie Lafond, Susan Ferri, Wilhelmine Jones, Janette Reimer, Dianne Burnand, Linda Lutz, Linda Manasterski, Susan McAleenan, Melba Athaide, Lise WillisHagen, Sandra Christiansen, Anne-Marie White, Dr. Hussam
Azzam, Catherine Badeau, Kristi Chorney, Elaine McIntyre, Joanne Ringer, Dr. Ken Henderson, Dr. Brian Sinclair, Dr. Lynette Bowes, Dr. Dorothy Barnard, the late Dr. Marilyn Dusseault, Dr. Bernard Girodias, Dr. Nirit Bernhard, Dr. Jane Healey, Dr. Darcy Beer, Dr. Adriana Condello, Dr. Brian Kelly, Dr. Leigh Wincott, Dr. Barrie MacLean and Dr. David Riddell for their dedication, leadership and participation. The authors also thank Elaine Orrbine for her support and the Canadian Association of Paediatric Health Centres for allowing the use and adaptation of its trigger tool for application in this study, and the Canadian Institute for Health Information for providing the data necessary for weighting analysis. Finally, the authors thank Dr. Mark Fleming for his early insights and guidance in the development and planning of the study and Dr. Alex Kiss for his assistance with statistical modelling. 